\title{
The effects of ramipril on sympathetic nervous system function in older patients with hypertension
}

\begin{abstract}
Background: There are important interactions between the renin-angiotensin system and the sympathetic nervous system. Therapy with angiotensin-converting enzyme (ACE) inhibitors may suppress sympathetic nervous system activity.

Objective: To test the hypothesis that long-term ACE inhibition by ramipril will suppress sympathetic nervous system activity and up-regulate $\alpha$-adrenergic receptor responsiveness in older patients with hypertension.

Methods: This placebo-controlled, double-blind randomized study was conducted at the University Hospital, General Clinical Research Center, University of Michigan Medical Center. Fifteen healthy older patients with mild to moderate hypertension received 8 weeks of ramipril therapy with doses ranging from 5 mg to $20 \mathrm{mg}$. The following measurements were obtained: plasma norepinephrine levels; norepinephrine kinetic parameters derived from plasma norepinephrine and ${ }^{3} \mathrm{H}$-norepinephrine levels obtained during infusion and disappearance of ${ }^{3} \mathrm{H}$-norepinephrine, including the extravascular norepinephrine release rate, norepinephrine clearance, spillover fraction, and volume of distribution; forearm blood flow; platelet membrane $\alpha_{2}$-receptor binding characteristics, and adenylyl cyclase activity.

Results: Although plasma norepinephrine levels increased in the subjects treated with ramipril, there were no significant differences from baseline in the rate of norepinephrine appearance into the vascular compartment $(P=.76)$ or in the rate of norepinephrine release into the extravascular compartment $(P=.92)$. In addition, no differences were observed in other norepinephrine kinetic parameters (norepinephrine spillover fraction, norepinephrine volume of distribution, or clearance) between the ramipril and placebo groups. Consistent with this, there was no apparent change in measures of vascular or platelet $\alpha$-adrenergic receptor responsiveness.

Conclusions: Ramipril therapy did not suppress systemic sympathetic nervous system activity, alter other norepinephrine kinetic parameters, or alter $\alpha$-adrenergic responsiveness in older patients with hypertension. (Clin Pharmacol Ther 1999;65:420-7.)
\end{abstract}

Cathy C. Lee, MD, Mohamad A. Sidani, MD, Robert V. Hogikyan, MD, MPH, and Mark A. Supiano, MD Ann Arbor, Mich

Aging is associated with an increase in systolic blood pressure, a decline in active renin concentration, and an increase in the level of sympathetic nervous system

From the University of Michigan Medical Center.

Supported in part by the General Clinical Research Center (NIH grant RR-00042); by the Geriatric Research, Education, and Clinical Center and the Medical Research Service of the Ann Arbor Department of Veterans Affairs Medical Center; and by a grant from the Pharmacia \& Upjohn Company.

Received for publication Sept 23, 1998; accepted Dec 14, 1998.

Reprint requests: Cathy C. Lee, MD, 1500 E Medical Center Drive, Room 1111, CCGCB, Ann Arbor, MI 48109. E-mail: clchopra@umich.edu

Copyright (C 1999 by Mosby, Inc.

$0009-9236 / 99 / \$ 8.00+0 \quad \mathbf{1 3 / 1 / 9 6 5 3 7}$ activity. ${ }^{1}$ Although the pathogenesis of hypertension in the elderly is unknown, older patients with hypertension are characterized by increased sympathetic nervous system activity, enhanced $\alpha$-adrenergic receptor responsiveness, ${ }^{2}$ and low active renin concentration. ${ }^{1}$ The pathophysiology of hypertension in the elderly may therefore involve altered regulation of sympathetic nervous system function.

The renin-angiotensin system has important interactions with the sympathetic nervous system. Angiotensin II has been shown to facilitate norepinephrine release from nerve terminals, block norepinephrine reuptake, elevate catecholamine synthesis, and potentiate the postsynaptic action of norepinephrine. ${ }^{3-5}$ In humans, 
plasma norepinephrine levels and muscle sympathetic activity have been shown to decrease in healthy subjects and in patients with hypertension and congestive heart failure who were treated with angiotensinconverting enzyme (ACE) inhibitors. ${ }^{6-8} \mathrm{ACE}$ inhibition may therefore decrease sympathetic nervous system activity.

The objective of this study was to test the hypothesis that long-term ACE inhibition by ramipril will suppress sympathetic nervous system activity and upregulate $\alpha$-adrenergic receptor responsiveness in older patients with hypertension. A minimal 2-compartment model was used to determine the parameters of norepinephrine kinetics, including the rate of norepinephrine release into the extravascular compartment $\left(\mathrm{NE}_{2}\right)$ as an estimate of systemic sympathetic nervous system activity. $\alpha$-Adrenergic receptor responsiveness was determined by norepinephrine-mediated forearm vasoconstriction and by platelet $\alpha_{2}$-receptor-mediated inhibition of adenylyl cyclase. We report that ramipril therapy does not suppress systemic sympathetic nervous system activity, alter other norepinephrine kinetic parameters, or alter $\alpha$-adrenergic responsiveness in older patients with hypertension.

\section{METHODS}

Subjects. Fifteen older subjects (10 men and 5 women; age range, 60 to 75 years; mean age \pm SD, 64 \pm 3 years) with mild to moderate hypertension in otherwise good general health were recruited through the Human Subjects Core of the University of Michigan Geriatrics Center and through newspaper advertisement. Each subject was screened before study entry with a medical history, physical examination, and laboratory tests, including a complete blood count, routine chemistries, and an ECG. Subjects were excluded from participation if they exceeded $150 \%$ of ideal body weight (Metropolitan Life Insurance tables, 1983); were being treated with either $\alpha$ - or $\beta$-adrenergic medications; had evidence for secondary hypertension discovered by routine clinical evaluation; had any history of angina, previous myocardial infarction, transient ischemic attack, previous stroke, claudication, syncope, diabetes mellitus, or Parkinson's disease; or had evidence from either history, physical examination, or laboratory results of other significant underlying medical or psychiatric illness. Subjects were either not receiving antihypertensive therapy or were receiving monotherapy. Subjects were eligible for the study if, after a 4-week observational period or withdrawal of antihypertensive therapy, their diastolic blood pressure measurements remained between 90 and 115 mm Hg and systolic blood pressure measurements remained below $220 \mathrm{~mm} \mathrm{Hg}$ when blood pressure measurements were taken on 3 separate occasions while they were sitting. The study was approved by the University of Michigan Human Use Committee, and each subject provided written informed consent.

Study protocol. The subjects were randomized in double-blind fashion into an intervention and control group by use of block randomization, with the ratio of intervention to placebo control of $2: 1$. Treatment with ramipril or placebo began after the 4-week run-in period during which subjects receiving antihypertensive therapy were withdrawn from their previous antihypertensive therapy. The subjects randomized to the intervention group were treated with ramipril starting at $10 \mathrm{mg} / \mathrm{day}$. The dose was increased by $10 \mathrm{mg}$ every week until the blood pressure target of less than 140/90 $\mathrm{mm} \mathrm{Hg}$ was achieved or a maximum dose of $40 \mathrm{mg} /$ day ramipril was reached. The subjects randomized to the placebo group received matching placebo tablets that were increased by 1 tablet every week up to a maximum of 4; that dose was then maintained for 4 weeks.

Studies were performed at the beginning and end of the 8-week treatment period. All subjects reported to the General Clinical Research Center of the University of Michigan Medical Center at 7:30 AM to control for any diurnal variation in norepinephrine metabolism ${ }^{9}$ or arterial $\alpha$-adrenergic tone. ${ }^{10}$ They were instructed to fast from $10 \mathrm{PM}$ the night before and to abstain from cigarettes, caffeine, and other known modulators of catecholamines for 12 hours before each study began. Subjects were studied while in the supine position in a quiet room maintained at a constant temperature from $23^{\circ} \mathrm{C}$ to $25^{\circ} \mathrm{C}$ to facilitate achieving an adequate baseline forearm blood flow (FABF). The proportion of body fat was determined by bioelectrical impedance (RJL Systems, Mt Clemens, Mich) ${ }^{11}$ and the waist/hip ratio was determined from an individual's waist and hip circumferences taken at the level of the umbilicus and the largest gluteal circumference, respectively. Forearm volume was measured with use of water displacement.

Systemic norepinephrine kinetics protocol. A 20gauge $1 / 4$-inch Insyte catheter was placed into the brachial artery of the nondominant arm. The catheter was connected to a pressure transducer (HewlettPackard 1290A quartz transducer, Hewlett-Packard, Andover, Mass). Mean arterial pressure (MAP) was determined from the electronically integrated area under the intra-arterial blood pressure curve from the Marquette telemetry system (Marquette Electronics Series 7700, Marquette Electronics, Inc, Milwaukee, Wis). An intravenous catheter was placed in the con- 
tralateral arm for infusion of $\left[{ }^{3} \mathrm{H}\right]$ norepinephrine. Before this infusion was begun, venous blood drawn from this site was collected into a plastic syringe that contained $1 \mathrm{~mL}$ of $0.25 \mathrm{~mol} / \mathrm{L}$ ethylenediaminetetraacetic acid to be used to prepare platelet membranes. The $\left[{ }^{3} \mathrm{H}\right]$ norepinephrine kinetics protocol was carried out as described previously with sampling from the brachial arterial catheter. ${ }^{12,13}$ Ten-milliliter blood samples were obtained (after discarding the first $1 \mathrm{~mL}$ blood from the line) at 40, 50, and 60 minutes during the infusion to determine plasma norepinephrine and $\left[{ }^{3} \mathrm{H}\right]$ norepinephrine concentrations. At 60 minutes, the $\left[{ }^{3} \mathrm{H}\right]$ norepinephrine infusion was stopped, and $10 \mathrm{~mL}$ blood samples were obtained at 1, 2, 4, 6, 8, 10, 12, 14, 16,18 , and 20 minutes to measure $\left[{ }^{3} \mathrm{H}\right]$ norepinephrine concentration. One of the 3 basic ECG limb leads was monitored.

Forearm blood flow protocol. Following the tracer $\left[{ }^{3} \mathrm{H}\right]$ norepinephrine infusion protocol, FABF was measured with use of venous occlusion plethysmography during an intra-arterial infusion protocol we have described previously. ${ }^{12,13}$ To establish a stable baseline, FABF readings were taken until 3 consecutive readings that represented similar FABF were obtained. To determine the effect of intra-arterial infusions of norepinephrine on FABF, norepinephrine (Levophed bitartrate, Sterling Drug Inc, New York, NY) was diluted in $5 \%$ dextrose to achieve stepwise increasing infusion doses of $1.25,5,20,80$, and $240 \mathrm{ng} / 100 \mathrm{~mL}$ forearm volume/min. Each norepinephrine dose was administered by an infusion pump (Harvard model 970T; Harvard Apparatus, South Natick, Mass) for 4 minutes before FABF was recorded during the fifth minute of each infusion. After the FABF measurement at the 240ng dose, the norepinephrine infusion was stopped.

Platelet membrane preparation. Platelet membrane lysates were prepared from 50 to $200 \mathrm{~mL}$ whole venous blood as described previously. ${ }^{14,15}$ An aliquot of the freshly prepared membrane lysate was used for adenylyl cyclase assays. The remainder of the sample was quick frozen in liquid nitrogen and stored at $-70^{\circ} \mathrm{C}$; radioligand binding studies were performed within 2 weeks of membrane preparation.

Radioligand equilibrium binding assays. [methyl1,3H]Yohimbine (72.5-90.0 Ci/mmol; Amersham, Arlington Heights, Ill), a specific $\alpha_{2}$-adrenergic receptor antagonist, was used to determine platelet membrane $\alpha_{2}$-adrenergic receptor antagonist binding properties and the imidazoline full $\alpha_{2}$-2-adrenergic receptor agonist $\left[{ }^{3} \mathrm{H}\right]-5$ bromo-6- $N(2-4,5$-dihydroimidazolyl) quinoxaline $\left(\left[{ }^{3} \mathrm{H}\right]\right.$ UK 14,304 or $\left[{ }^{3} \mathrm{H}\right]$ bromoxidine; 60.0 to 93.9 $\mathrm{Ci} / \mathrm{mmol}$, New England Nuclear, Boston, Mass) was used to determine platelet membrane $\alpha_{2}$-adrenergic receptor agonist binding properties with use of methods we have described previously. ${ }^{14}$ In human platelet membranes, $\left[{ }^{3} \mathrm{H}\right]$ bromoxidine has been shown to bind to 1 high-affinity site, ${ }^{16}$ which is functionally coupled to adenylyl cyclase. ${ }^{17}$ We have previously shown that analysis of $\left[{ }^{3} \mathrm{H}\right]$ bromoxidine specific binding over the concentration range and assay conditions used in these experiments identifies the high-affinity binding state. ${ }^{14}$

Adenylyl cyclase assays. Platelet membrane basal adenylyl cyclase activity was determined with use of freshly prepared membranes at the beginning (time 0 ) and at the conclusion of a 15 -minute incubation at $30^{\circ} \mathrm{C}$ as described previously. ${ }^{14,15}$ Stimulation of adenylyl cyclase activity was achieved with the addition of 25$\mathrm{mmol} / \mathrm{L}$ sodium fluoride $(\mathrm{NaF})$ and its $\alpha_{2}$-adrenergic receptor-medicated inhibition by $10^{-9}$ to $10^{-4} \mathrm{~mol} / \mathrm{L}$ epinephrine. The concentration of cAMP in the assay tubes was measured by radioimmunoassay. ${ }^{15}$ The concentration of cAMP in the 0-time basal activity condition was subtracted from the 15-minute basal, NaFstimulated, and epinephrine inhibition conditions so that the values would reflect only the accumulation of cAMP during the 15-minute incubation period. The extent of epinephrine-mediated inhibition at each epinephrine concentration was determined as the percentage decrease in cAMP accumulation in the presence of epinephrine and $\mathrm{NaF}$ from the NaF-stimulated activity without epinephrine.

Plasma catecholamine analytical methods. Arterial or arterialized-venous blood samples were collected into chilled plastic tubes that contained ethylene glycolbis(B-aminoethyl ether)- $N, N, N^{\prime}, N^{\prime}$-tetraacetic acid (EGTA) and reduced glutathione. The tubes were kept on ice until centrifugation at $4^{\circ} \mathrm{C}$. Plasma samples were stored at $-70^{\circ} \mathrm{C}$ until assayed. Plasma norepinephrine and epinephrine were quantified by a single-isotope radioenzymatic assay, with all samples from a given subject analyzed in the same assay. ${ }^{18}$ The intra-assay coefficient of variation for norepinephrine in this assay is 5\%. Alumina extraction of plasma samples and measurement of $\left[{ }^{3} \mathrm{H}\right]$ norepinephrine levels were performed as described previously. 19,20

Data and statistical analysis. Steady-state, 1-compartment, kinetic parameters (the rate of appearance into $\left[\mathrm{NE}_{\mathrm{AP}}\right]$ and clearance from $\left[\mathrm{NE}_{\mathrm{CL}}\right]$ the circulation) were calculated from steady-state plasma levels of ${ }^{3} \mathrm{H}$ norepinephrine and norepinephrine as described previously. ${ }^{19}$ Compartmental analysis of norepinephrine kinetics was performed with the previously described minimal 2-compartment model. ${ }^{19}$ The quantity of norepinephrine in each compartment (norepinephrine mass 
Table I. Hemodynamic characteristics

\begin{tabular}{|c|c|c|c|c|c|c|}
\hline & \multicolumn{3}{|c|}{ Intervention $(n=11)$} & \multicolumn{3}{|c|}{ Control $(n=4)$} \\
\hline & Baseline & Ramipril & $P$ Value & Baseline & Placebo & $P$ Value \\
\hline MAP (mm Hg) & $119 \pm 4$ & $112 \pm 5$ & .01 & $127 \pm 6$ & $130 \pm 9$ & .34 \\
\hline Heart rate (beats/min) & $64 \pm 3$ & $63 \pm 2$ & .26 & $74 \pm 7$ & $76 \pm 6$ & .53 \\
\hline $\mathrm{FABF}(\mathrm{mL} / \mathrm{min})$ & $3.6 \pm 0.5$ & $3.6 \pm 0.4$ & .95 & $4.9 \pm 1.3$ & $6.3 \pm 0.2 *$ & .92 \\
\hline FAVR (units) $\dagger$ & $41 \pm 7$ & $35 \pm 3$ & .28 & $32 \pm 8$ & $21 \pm 2$ & .71 \\
\hline
\end{tabular}

MAP, Mean arterial blood pressure, derived from supine intra-arterial blood pressure recording; FABF, forearm blood flow.

$* \mathrm{n}=2$.

$\dagger$ FAVR, Mean arterial blood pressure/FABF.

Table II. Plasma catecholamines and norepinephrine kinetic parameters

\begin{tabular}{|c|c|c|c|c|c|c|}
\hline & \multicolumn{3}{|c|}{ Intervention $(n=10)$} & \multicolumn{3}{|c|}{ Control $(n=3)$} \\
\hline & Baseline & Ramipril & $P$ Value & Baseline & Placebo & $P$ Value \\
\hline Plasma norepinephrine $(\mathrm{pg} / \mathrm{mL})$ & $359 \pm 36$ & $396 \pm 41$ & .01 & $350 \pm 19$ & $349 \pm 37$ & .98 \\
\hline Plasma epinephrine (pg/mL) & $64 \pm 10$ & $52 \pm 4$ & .44 & $46 \pm 10$ & $55 \pm 10$ & .14 \\
\hline \multicolumn{7}{|l|}{ One-compartment model } \\
\hline $\mathrm{NE}_{\mathrm{AP}}\left(\mu \mathrm{g} / \mathrm{min} / \mathrm{m}^{2}\right)$ & $0.37 \pm 0.04$ & $0.43 \pm 0.05$ & .38 & $0.38 \pm 0.04$ & $0.42 \pm 0.05$ & .63 \\
\hline $\mathrm{NE}_{\mathrm{CL}}\left(\mathrm{mL} / \mathrm{min} / \mathrm{m}^{2}\right)$ & $2074 \pm 99$ & $2037 \pm 119$ & .81 & $2503 \pm 129$ & $2400 \pm 104$ & .57 \\
\hline \multicolumn{7}{|l|}{ Two-compartment model } \\
\hline $\mathrm{NE}_{2}\left(\mu \mathrm{g} / \mathrm{min} / \mathrm{m}^{2}\right)$ & $2.81 \pm 0.35$ & $2.84 \pm 0.32$ & .92 & $2.25 \pm 0.16$ & $2.63 \pm 0.20$ & .11 \\
\hline $\mathrm{MCR}_{1}\left(\mathrm{~mL} / \mathrm{min} / \mathrm{m}^{2}\right)$ & $1114 \pm 52$ & $1073 \pm 50$ & .41 & $1211 \pm 38$ & $1186 \pm 95$ & .86 \\
\hline $\mathrm{Q}_{1}\left(\mu \mathrm{g} / \mathrm{m}^{2}\right)$ & $0.49 \pm 0.08$ & $0.48 \pm 0.06$ & .90 & $0.40 \pm 0.03$ & $0.52 \pm 0.12$ & .28 \\
\hline $\mathrm{Q}_{2}\left(\mu \mathrm{g} / \mathrm{m}^{2}\right)$ & $75 \pm 11$ & $94 \pm 35$ & .63 & $45 \pm 3$ & $68 \pm 3$ & .29 \\
\hline $\mathrm{NE}_{\mathrm{SF}}(\%)$ & $14 \pm 0.9$ & $14 \pm 1$ & .95 & $17 \pm 1$ & $16 \pm 2$ & .63 \\
\hline $\mathrm{V}_{1}\left(\mathrm{~L} / \mathrm{m}^{2}\right)$ & $2.7 \pm 0.3$ & $2.5 \pm 0.2$ & .51 & $2.5 \pm 1$ & $2.9 \pm 0.3$ & .39 \\
\hline
\end{tabular}

Data are mean values \pm SEM.

$\mathrm{NE}_{\mathrm{AP}}$, Rate of norepinephrine appearance into circulation; $\mathrm{NE}_{\mathrm{CL}}$, rate of norepinephrine clearance from circulation; $\mathrm{NE}_{2}$, extravascular norepinephrine release rate; $\mathrm{MCR}_{1}$, norepinephrine metabolic clearance rate from compartment $1 ; \mathrm{Q}_{1}$ and $\mathrm{Q}_{2}$, norepinephrine mass in compartments 1 and 2; NE $\mathrm{SF}_{\mathrm{F}}$, norepinephrine spillover fraction; $\mathrm{V}_{1}$, norepinephrine volume of distribution in compartment 1 ; compartment 1 , vascular-containing compartment; compartment 2 , extravascular compartment.

in the intravascular compartment $\left[\mathrm{Q}_{1}\right]$ and in the extravascular compartment $\left.\left[\mathrm{Q}_{2}\right]\right)$, the rate of norepinephrine appearance into each compartment $\left(\mathrm{R}_{12}\right.$ into compartment 1 and $\mathrm{NE}_{2}$ into compartment 2), the norepinephrine metabolic clearance rate from compartment $1\left(\mathrm{MCR}_{1}\right)$, the norepinephrine spillover fraction $\left(\mathrm{NE}_{\mathrm{SF}}\right)$, and the volume of distribution of norepinephrine in compartment $1\left(\mathrm{~V}_{1}\right)$ were calculated from the 2compartment model as functions of the estimated transfer rate coefficients as described previously. ${ }^{19}$

Baseline and posttreatment changes within each group were compared by the paired Student $t$ tests. Heart rate, MAP, norepinephrine kinetic parameters, platelet membrane adenylyl cyclase activity, and equilibrium binding studies were analyzed with SAS (SAS Institute, Inc, Cary, NC). To adjust for any existing differences in baseline values between the control and intervention groups, multiple regression models, which included the baseline values as a covariate, were cre- ated to compare the posttreatment values between intervention (ramipril) and control (placebo) groups.

Dose-response data for norepinephrine was analyzed as the percentage change in FABF from the baseline value obtained before the infusion with use of repeatedmeasures ANOVA. MAP was determined just before each FABF measurement. Forearm vascular resistance was calculated as the MAP divided by the FABF and is presented in arbitrary units. Dose-response curves for adenylyl cyclase inhibition by epinephrine were also analyzed by ANOVA between baseline and postramipril treatment groups.

Values are presented as mean values \pm SEM except for the subject characteristics, which are presented as mean values $\pm \mathrm{SD}$. A value of $P<.05$ was selected to indicate statistical significance. Paired Student $t$ tests were used to compare differences in age, body mass index, waist/hip ratio, percent body fat, MAP, and heart rate between the control and intervention groups. 


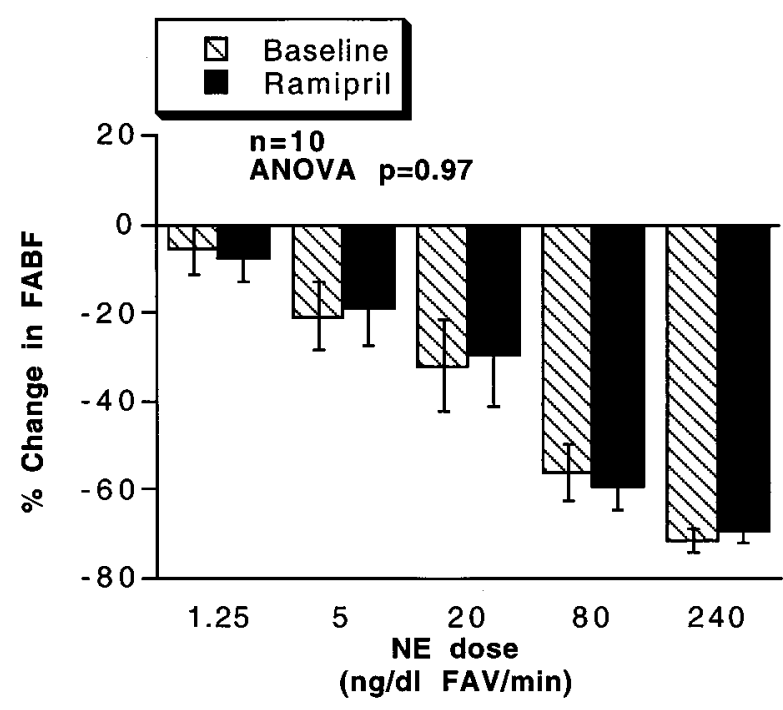

Figure 1. Group mean data for percentage change of forearm blood flow (FABF) from baseline in response to increasing doses of intra-arterial norepinephrine (NE) infusion in older subjects with hypertension at baseline and after 8 weeks of ramipril. A significant treatment effect was not shown by ANOVA $(P=.97)$. FAV, Forearm volume.

\section{RESULTS}

Subject characteristics. Ten men and 5 women participated in the study. The mean age of these subjects was 65 years, with an age range from 60 to 73 years. The subject group was somewhat overweight as reflected in their body mass index $\left(28.1 \pm 3.5 \mathrm{~kg} / \mathrm{m}^{2}\right)$, waist/hip ratio $(0.87 \pm 0.09)$, and percentage of body fat $(28.6 \% \pm 7.0 \%)$. There were no statistically significant differences with respect to age, gender distribution, body mass index, waist/hip ratio, or percentage of body fat between the control and intervention subject groups.

Hemodynamic characteristics. The ramipril dose achieved in the treatment group ranged from 5 to $20 \mathrm{mg}$, with a mean dose of $12 \pm 2 \mathrm{mg}$. Treatment with ramipril significantly decreased MAP $(P=.01)$, whereas treatment with placebo did not significantly change the MAP in the control group $(P=.34$; Table I). The placebo group tended to have a higher baseline heart rate and MAP compared with the intervention group, but these differences were not statistically significant.

Plasma catecholamine levels and systemic norepinephrine kinetics. There was a significant increase in plasma norepinephrine levels within the ramipril group after 8 weeks of ramipril therapy that was not observed in the placebo group (Table II). However, when the statistical analysis is adjusted for the baseline measurements with multiple regression, there were no posttreat- ment differences between the ramipril group compared with the placebo group for either plasma norepinephrine $(P=.25)$ or epinephrine levels $(P=.19)$. No interactions were identified between the groups and the baseline measurements. Norepinephrine kinetics results were not obtained from 1 ramipril subject and 1 placebo subject because of technical difficulties. Analysis of steady-state norepinephrine kinetics with the 1-compartment model showed no significant differences in the ramipril group compared with the placebo group for $\mathrm{NE}_{\mathrm{AP}}$ or $\mathrm{NE}_{\mathrm{CL}}$, even after adjustments were made for the baseline measurements $\left(\mathrm{NE}_{\mathrm{AP}}, P=.76 ; \mathrm{NE}_{\mathrm{CL}}\right.$, $P=.92)$. There were no treatment effects noted for $\mathrm{NE}_{2}$, $\mathrm{MCR}_{1}$, norepinephrine mass in compartments 1 or 2 , norepinephrine spillover fraction, or the norepinephrine volume of distribution after treatment within the ramipril group and placebo group separately or among the 2 groups when adjusted for baseline.

FABF during vasoactive infusions. There were no ramipril-placebo group differences in either baseline FABF $(P=.27)$ or forearm vascular resistance $(P=.48)$ measured before the intra-arterial infusion protocol (Table I). The change in FABF at baseline and after treatment in response to each norepinephrine intraarterial infusion dose is shown for the ramipril group (Figure 1). There was a significant norepinephrine dose effect $(P<.0001)$. However, there was no significant difference in the percentage change in FABF between baseline and post-ramipril treatment (ANOVA, $P=$ .97). Complete norepinephrine dose-response results were not available for 1 subject in the ramipril group and 2 subjects in the placebo group. Among the subjects receiving placebo, there was a similar norepinephrine dose effect and no apparent baseline-placebo difference in percentage change in FABF, but statistical analysis was not performed because only 2 subjects in the placebo group completed this protocol.

Platelet membrane adenylyl cyclase activity. There were no significant group differences $(P=.61)$ in the basal rate of cAMP production in the platelet membrane lysates during the 15-minute incubation period (after subtracting the cAMP concentration present in the membrane samples at time 0 of the assay; Table III). In addition, the degree of stimulation above the basal level by $\mathrm{NaF}$ was also similar between the 2 groups when adjusted for the baseline measurements $(P=.86)$. The dose-response effect for epinephrine-mediated inhibition of NaF-stimulated adenylyl cyclase activity identified a significant dose effect for epinephrine-mediated inhibition, but no significant difference between the baseline measures and either after ramipril (ANOVA, $P=.79$ ) or after placebo (ANOVA, $P=.66$ ) for the per- 
Table III. Platelet membrane $\alpha_{2}$-receptor binding characteristics and adenylyl cyclase activity

\begin{tabular}{|c|c|c|c|c|c|c|}
\hline & \multicolumn{3}{|c|}{ Intervention $(n=11)$} & \multicolumn{3}{|c|}{ Control $(n=4)$} \\
\hline & Baseline & Ramipril & $P$ Value & Baseline & Placebo & $P$ Value \\
\hline \multicolumn{7}{|c|}{ Platelet membrane $\alpha_{2}$-receptor binding characteristics } \\
\hline Yohimbine $\mathrm{B}_{\max }(\mathrm{fmol} / \mathrm{mg}$ protein $)$ & $144 \pm 14$ & $115 \pm 12$ & .11 & $105 \pm 13$ & $119 \pm 20$ & .56 \\
\hline Yohimbine $\mathrm{K}_{\mathrm{d}}(\mathrm{pmol} / \mathrm{L})$ & $2.1 \pm 0.2$ & $1.6 \pm 0.1$ & .01 & $1.5 \pm 0.09$ & $1.8 \pm 0.03$ & .04 \\
\hline Bromoxidine $\mathrm{B}_{\max }$ (fmol/mg protein) & $33.0 \pm 6.4$ & $23.9 \pm 6.0$ & .02 & $17 \pm 9.4$ & $8.8 \pm 5.2$ & .90 \\
\hline Bromoxidine $\mathrm{K}_{\mathrm{d}}(\mathrm{nmol} / \mathrm{L})$ & $2.8 \pm 0.6$ & $1.9 \pm 0.3$ & .34 & $1.7 \pm 0.2$ & $1.8 \pm 0.7$ & .89 \\
\hline \multicolumn{7}{|l|}{ Platelet membrane adenylyl cyclase activity } \\
\hline Basal (pmol/mg/15 min) & $570 \pm 76$ & $517 \pm 51$ & .55 & $648 \pm 121$ & $459 \pm 160$ & .37 \\
\hline NaF-stimulated (pmol/mg/15 min) & $2185 \pm 189$ & $2050 \pm 135$ & .39 & $2451 \pm 247$ & $2085 \pm 464$ & .54 \\
\hline Maximal epinephrine-mediated inhibition (\%) & $-50.9 \pm 4.3$ & $-53.9 \pm 1.2$ & .49 & $-53.3 \pm 2.0$ & $-62.4 \pm 2.4$ & .13 \\
\hline
\end{tabular}

$\mathrm{B}_{\max }$, Maximum receptor binding density; $\mathrm{K}_{\mathrm{d}}$, dissociation constant; $\mathrm{NaF}$, sodium fluoride.

centage of inhibition from the NaF-stimulated level. There were also no significant differences in the maximal extent of adenylyl cyclase inhibition (Table III).

Equilibrium binding studies. The receptor binding densities and dissociation constants from equilibrium binding studies for the antagonist $\left[{ }^{3} \mathrm{H}\right]$ yohimbine and the agonist $\left[{ }^{3} \mathrm{H}\right]$ bromoxidine are presented in Table III. An insufficient platelet protein yield prevented $\left[{ }^{3} \mathrm{H}\right]$ bromoxidine studies from being done in 2 subjects in the ramipril group and 2 subjects in the placebo group. When the baseline measurements are accounted for with regression analysis, there were no significant posttreatment group differences in the maximum receptor binding density $\left(\mathrm{B}_{\max }\right)$ or dissociation constant $\left(\mathrm{K}_{\mathrm{d}}\right)$ for either the antagonist radioligand $\left[{ }^{3} \mathrm{H}\right]$ yohimbine $\left(\mathrm{B}_{\max }\right.$, $\left.P=.22 ; \mathrm{K}_{\mathrm{d}}, P=.20\right)$ or the agonist radioligand $\left[{ }^{3} \mathrm{H}\right]$ bromoxidine $\left(\mathrm{B}_{\max }, P=.48 ; \mathrm{K}_{\mathrm{d}}, P=.80\right)$.

\section{DISCUSSION}

The results from this study do not support the hypothesis that ramipril suppresses sympathetic nervous system activity in older patients with hypertension. After 8 weeks of ramipril therapy, there was a significant reduction in blood pressure, whereas no change in blood pressure was identified in the placebo-treated control group. Although plasma norepinephrine levels increased in the ramipril treated subjects, the findings from the norepinephrine kinetics studies in these subjects did not show an increase in $\mathrm{NE}_{2}$, the rate of norepinephrine release into the extravascular compartment. These findings were consistent with the 1-compartment model analysis, showing no difference in $\mathrm{NE}_{\mathrm{AP}}$ between the ramipril and placebo groups. In addition, there was no significant effect of ramipril on other norepinephrine kinetic parameters. Consistent with the lack of change in sympathetic nervous system activity, the results did not show any effect of ramipril on the adrenergic-mediated decrease in FABF or inhibition of platelet membrane adenylyl cyclase activity.

Animal and human studies have shown interactions between the sympathetic nervous system and the reninangiotensin system. In isolated rat mesenteric arteries, Malik and Nasjletti ${ }^{4}$ demonstrated that angiotensin II potentiates the vasoconstrictor responses to sympathetic nerve stimulation and to injected norepinephrine. With use of in vivo and in vitro techniques, Clough et $\mathrm{al}^{5}$ showed in rats that angiotensin II facilitates adrenergic neurotransmission and that inhibitors of the reninangiotensin system attenuate neurogenic vasoconstriction. Consistent with these observations, several studies have suggested that therapy with ACE inhibitors may decrease sympathetic nervous system activity. Noll ${ }^{6}$ found that muscle sympathetic activity decreased after single-dose captopril administration in healthy volunteers. Plasma norepinephrine levels were also found to be decreased in patients with hypertension treated with quinapril, ${ }^{7}$ captopril, ${ }^{21}$ or single-dose benazepril. ${ }^{8}$ Other studies have failed to identify changes in plasma norepinephrine level immediately following $22-24$ or after short-term ${ }^{25,26}$ ACE inhibitor therapy.

The results from these studies led us to hypothesize that long-term ACE inhibitor therapy with ramipril would decrease systemic sympathetic nervous system activity in older patients with hypertension. We chose this study population, which is characterized by relatively high levels of sympathetic nervous system activity, to increase the likelihood of detecting suppression of sympathetic nervous system activity. ${ }^{2}$ In contrast to the studies cited above, we elected to characterize response to long-term ( 8 weeks) as opposed to acute single-dose therapy. In addition, recognizing the complex metabolism of norepinephrine, we performed nor- 
epinephrine kinetics studies to avoid reliance on plasma norepinephrine levels to reflect sympathetic nervous system activity. We report that plasma norepinephrine levels increased after 8 weeks of therapy with ramipril. However, there was no significant increase in the rate of norepinephrine release into the extravascular compartment $\left(\mathrm{NE}_{2}\right)$, nor were there significant differences in other parameters of norepinephrine metabolism. The increase in plasma norepinephrine levels may be accounted for by the slight, although not statistically significant, reductions in $\mathrm{MCR}_{1}$ and $\mathrm{V}_{1}$. We therefore conclude that long-term ACE inhibition by ramipril appears to have no effect on systemic sympathetic nervous system activity in older patients with hypertension.

To the extent that no change in sympathetic nervous system activity was identified in our subjects, it follows that there were no significant differences in the measures of $\alpha_{2}$-receptor responsiveness. There were no significant changes in resting forearm blood flow or forearm vascular resistance after ramipril therapy. The effect of intrabrachial artery norepinephrine infusion to decrease forearm blood flow was similar to baseline after ramipril therapy. Many studies have used platelet $\alpha_{2}$-adrenergic-receptors as an accessible model of vascular $\alpha$-adrenergic receptor function. ${ }^{27}$ To that end, in parallel with the vascular responsiveness results, there was also no effect of ramipril therapy on $\alpha_{2}$-mediated inhibition of platelet membrane adenylyl cyclase activity. This was the case despite a tendency for there to be reduction in both total (yohimbine $\mathrm{B}_{\max }$ ) and highaffinity (bromoxidine $\mathrm{B}_{\max }$ ) receptor binding densities . These slight reductions in receptor binding densities might have resulted from the increase in plasma norepinephrine levels after ramipril therapy because exposure of platelets to increased plasma norepinephrine would be expected to regulate their $\alpha_{2}$-receptor function. One study has also reported a reduction in total platelet $\alpha_{2}$-receptor density after 16 weeks of therapy with captopril; however, no change in plasma norepinephrine levels was observed in this group. ${ }^{21}$ Additional studies will be required to determine whether the absence of change in $\alpha_{2}$-mediated inhibition of adenylyl cyclase reflects abnormal $\alpha_{2}$-receptor regulation or insufficient exposure to agonist.

We acknowledge several potential limitations inherent in our study. Although conducted in a placebocontrolled, double-blind randomized manner, this study did not test for a change in sympathetic nervous system activity during a comparable reduction in blood pressure with an agent that does not affect the reninangiotensin system. It might be expected that sympathetic nervous system activity would be increased with blood pressure reduction. Therefore we cannot exclude the possibility that there was a sympatholytic effect of ACE inhibition that prevented an increase in sympathetic nervous system activity. The results in this study may be specific to the ACE inhibitor ramipril and may not necessarily generalize to other ACE inhibitors. In addition, the norepinephrine kinetics study we conducted provides an assessment of systemic but not regional level of sympathetic nervous system activity. We cannot rule out the possibility that ramipril therapy led to suppression of regional, organ-specific sympathetic nervous system activity, without affecting overall systemic level of activity.

In summary, we did not find that long-term ramipril therapy suppresses systemic sympathetic nervous system activity in older patients with hypertension. The 2-compartment model analysis of systemic norepinephrine kinetics showed that there were no changes in $\mathrm{NE}_{2}$, norepinephrine clearance, norepinephrine spillover fraction, or the norepinephrine volume of distribution. Despite an increase in plasma norepinephrine levels, the stability of the rate of norepinephrine release into the extravascular compartment $\left(\mathrm{NE}_{2}\right)$ supports the conclusion that there was no change in sympathetic nervous system activity with ramipril therapy. Consistent with this, there was no apparent change in vascular or platelet $\alpha$-adrenergic receptor responsiveness. On the basis of these results, we conclude that the blood pressure-lowering effect of ramipril in older subjects with hypertension occurs independently of effects on sympathetic nervous system function.

We thank Jodi Krueger and Marla Smith for their technical assistance, Kathy Jarvenpa, RN, and the staff of the General Clinical Research Center for their care of our subjects during this study, and Andrzej Galecki, MD, PhD, for his statistical advice. Ramipril and the matching placebo were donated by Pharmacia \& Upjohn.

\section{References}

1. Beck LH. Aging changes in renal function. In: Hazzard WR, Bierman EL, Blass JP, Ettinger WH Jr, Halter JB, editors. Principles of geriatric medicine and gerontology. 3rd ed. New York: McGraw-Hill; 1994. p. 615-24.

2. Supiano MA, Hogikyan RV, Sidani MA, Galechi AT, Krueger JL. Heightened sympathetic nervous system activity and $\alpha$-adrenergic responsiveness in older hypertensive humans. Am J Physiol 1999;276:E519-29.

3. Ball SG. The sympathetic nervous system and converting enzyme inhibition. J Cardiovasc Pharmacol 1989;13 (suppl 3):S17-21.

4. Malik KU. Nasjletti A. Facilitation of adrenergic transmission by locally generated angiotensin II in rat mesenteric arteries. Circ Res 1976;38:26-30. 
5. Clough D, Collis M, Conway J, Halton R, Keddie J. Interaction of angiotensin-converting enzyme inhibitors with the function of the sympathetic nervous system. Am J Cardiol 1982;49:1410-4.

6. Noll G. Differential effects of captopril and nitrates on muscle sympathetic nerve activity in volunteers. Circulation 1997;95:2286-92.

7. Prats MV, Serra MM, Artero JB, Benito GM, Escuder PT, Nicolas JMM. Quinapril ACE-inhibition effects on adrenergic parameters in moderate essential hypertension. Kidney Int 1996;49:(suppl 55):S104-6.

8. Giannattasio C, Cattaneo BM, Omboni S, Seravalle G, Bolla G, Turolo L, et al. Sympathomoderating influence of benazepril in essential hypertension. J Hypertens 1992;10:373-8.

9. Prinz PN, Halter JB, Benedetti C, Raskind M. Circadian variation of plasma catecholamines in young and old men: relation to rapid eye movement and slow wave sleep. J Clin Endocrinol Metab 1979;49:300-4.

10. Panza JA, Epstein SE, Quyyumi AA. Circadian variation in vascular tone and its relation to $\alpha$-sympathetic vasoconstrictor activity. N Engl J Med 1991;325:986-90.

11. Lukaski HC, Bolonchuk WW, Hall CB, Siders W. Validation of tetrapolar bioelectrical impedance method to assess human body composition. J Appl Physiol 1986;60:1327-32.

12. Hogikyan RV, Supiano MA. Homologous upregulation of human arterial $\alpha$-adrenergic responses by guanadrel. J Clin Invest 1993;256:1429-35.

13. Hogikyan RV, Supiano MA. Arterial $\alpha$-adrenergic responsiveness is decreased and sympathetic nervous system activity is increased in older human. Am J Physiol 1994; 266:E717-24.

14. Supiano MA, Hogikyan RV. High affinity platelet $\alpha_{2^{-}}$ adrenergic receptor density is decreased in older humans. J Gerontol 1993;48:B173-9.

15. Supiano MA, Neubig RR, Linares OA, Halter JB, Rosen SG. Effects of low sodium diet on regulation of platelet alpha ${ }_{2}$-adrenergic receptors in young and elderly humans. Am J Physiol 1989;256:E339-44.

16. Neubig RR, Gantzos RD, Brasier RS. Agonist and antagonist binding to $\alpha_{2}$-adrenergic receptors in purified membranes from human platelets. Mol Pharmol 1985;28:475-86.
17. Thomsen WJ, Jacquez JA, Neubig RR. Inhibition of adenylate cyclase is mediated by the high affinity conformation of the $\alpha_{2}$-adrenergic receptor. Mol Pharmacol 1988;34:814-22.

18. Evans MI, Halter JB, Porte D. Comparisons of doubleand single-isotope enzymatic derivative methods for measuring catecholamines in human plasma. Clin Chem 1978;24:567-70.

19. Linares OA, Jacquez JA, Zech LA, Smith MJ, Sanfield JA, Morrow LA, et al. Norepinephrine metabolism in humans. J Clin Invest 1987;80:1332-41.

20. Morrow LA, Linares OA, Hill TJ, Sanfield JA, Supiano MA, Rosen SG, et al. Age differences in the plasma clearance mechanisms for epinephrine and norepinephrine in humans. J Endocrinol Metab 1987;65:508-11.

21. Muller R, Steffer HM, Weller P, Kugel C, Freiheit T, Krone W. Changes in plasma norepinephrine concentration and thrombocyte $\alpha_{2}$-adrenoceptor density during long-term antihypertensive therapy with nitrendipine and captopril. J Cardiovasc Pharmacol 1994;24:429-33.

22. Becker RHA, Struthers AD, Brown MJ. Effect of captopril on changes in plasma noradrenaline induced by sodium nitroprusside. Br J Clin Pharmacol 1986;22:409-13.

23. Nicholls MG, Espiner EA, Miles KD, Zweifler AJ, Julius $\mathrm{S}$. Evidence against an interaction of angiotensin II with the sympathetic nervous system in man. Clin Endocrinol 1981;15:423-30.

24. Millar JA, Derkx FHM, McLean K, Reid JL. Pharmacodynamics of converting enzyme inhibition: the cardiovascular, endocrine and autonomic effects of MK421 (enalapril) and MK521. Br J Clin Pharmacol 1982;14: 347-55.

25. Clementi WA, Durst NL, McNay JL, Keeton TK. Captopril modifies the hemodynamic and neuroendocrine responses to sodium nitroprusside in hypertensive patients. Hypertension 1986;8:229-37.

26. Philipp T, Sharma AM, Thiede H, Kribben A. Sympathetic nervous activity and noradrenaline reactivity during angiotensin converting enzyme inhibition. Am J Cardiol 1987;59:55D-9D.

27. Michel MC, Brodde O, Insel PA. Peripheral adrenergic receptors in hypertension. Hypertension 1990;16:107-20. 